\title{
SUPERCONDUCTING CABLES FOR POWER TRANSMISSION
}

\author{
P.A.S.Sai Sushma \\ Department OF EEE \\ RAJAM
}

\author{
G.Chandra Sekhar \\ Department OF EEE \\ RAJAM
}

\begin{abstract}
Large-capacity superconducting power cables are in the spotlight to replace existing underground transmission power cables for power transmission. The motive for the development of these superconducting power cables is to reduce the transmission losses during the transmission. By comparing the loss components in conventional as well as superconducting cables, it is concluded that high load connections are necessary to obtain energy saving by the use of HTS cables. High temperature semiconductor cables, work for the reduction of the increase of temperature in the conducting cables. High temperature semiconductor, with liquid nitrogen and gaseous helium system enables cable operation which is to reduce the fault in the system. In comparison with the conventional cables, the high temperature conducting cables have merits in small volume, high current density, environmental friendly, safer, no leakage of electromagnetic field outside of the cable, small impedance, low maintenance cost, low frequency of failure which brings a new power transmission system for the future smart grid. The use of ceramic-based HTS in the power transmission system achieves low loss transmission while eliminating resistive losses, supplant copper electrical conductors and more fundamental change to electric power transmission technologies.
\end{abstract}

Keywords: superconducting materials, liquid nitrogen insulation, cold dielectric, warm dielectric, heat shrink.

\section{INTRODUCTION}

With the increasing demand in the electric power, we have to increase the technology for power transmission in order to reduce the losses. One of the existing power transmission system, Underground Cables resulting in advantages over the overhead transmission line. Superconducting Cables are the trending technology in the power transmission system which is under the final stage of its research and getting ready of its installation in order to reduce the existing power losses during the transmission of large amount of power.

Superconducting cables are attracting compared to the conventional power cables as there electric resistance becomes zero at certain temperature. This helps the cable to transmit five to six times more power that is transmitted by the same sized conventional cable.

Despite of these advantages design, installation and fabrication of these Superconducting cables becomes difficult as these depend upon the High Temperature Superconducting(HTS) materials. High Temperature Superconducting(HTS) cables have operational benefits due to its nitrogen cooling system[1]. This results in environmental friendly medium. In some situations where higher power densities are required, it is necessary to operate High Temperature Superconducting (HTS) cables at temperatures lower than the LN2 range.[1] Gaseous helium (GHe) circulation has been demonstrated as viable option for cooling HTS power cables as it has low dielectric strength when compared to nitrogen. During the process of development of the Superconducting Cable some companies are in the process of development of 3 in 1 power cable which reduces the electromagnetic field leakage to reduce the losses during the transmission.

Presently there are two main types of superconducting power cables, distinguished by the type of dielectric used which are warm dielectric design and cold dielectric design used for the power transmission.

\section{DESIGN OF SUPERCONDUCTING CABLE}

The design of HTS cable has some of the challenging design constraints that do not exist in the room temperature power cables. These include the need of cryogenic(Low Temperature) 


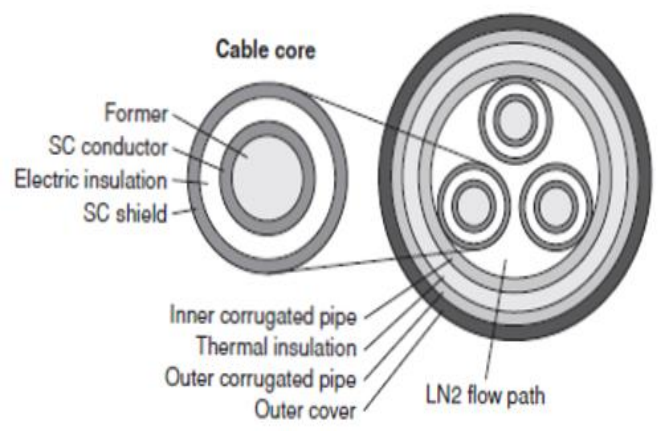

Figure 1 parts of a cable

operating environment. The first used and simplest form ofdesign introduced for Superconducting Cable is Warm Dielectric Cable.[4] It used a cryostat with a conventional electrical insulation Outside. The HTS wires are wrapped around a copper core and in placed in a tube in which it is flowing coolant, i.e., liquid nitrogen. The copper core at the center is the protection element. This carriers the current for short period when critical current of the superconductor is exceeded.

By this design least amount of HTS cable is used for the transmission of the given amount of power. It has a high inductance and external magnetic field. If the three phases are in close proximity, then the magnetic field produced by one phase causes hysteresis losses in the other phase, this leads to high losses. Due to these high losses, a cable with two layers of superconductor, with the outer layer acting as a magnetic shield for the adjacent cable, was introduced. In the warm dielectric cable there no superconducting shield present, hence no magnetic shielding effect can be expected during operation. [3] As a result, higher electrical losses and higher cable inductance are significant drawbacks relative to the other superconducting cable designs. No such requirements exist for cold dielectric cables.

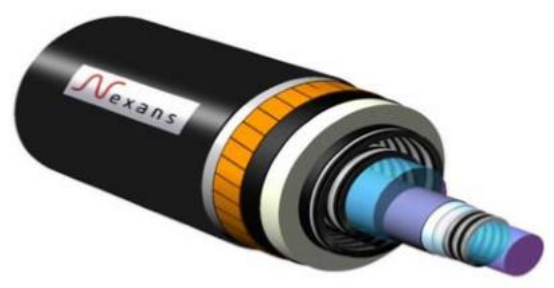

Figure 2: warm dielectric cable

This cold dielectric design is used mostly for the design of the Superconducting Cables. In this design the two HTS layers are insulated from each other by a cold dielectric.[5] Liquid Nitrogen coolant contact both layers, providing both cooling and dielectric insulation between the conductor and the outer layer. As compared to the warm dielectric design, it has low inductance, a higher current carrying capacity, it reduces the AC transmission losses, and low stray magnetic fields.

Perhaps the most effective AC power transmission cable design is three-conductor concentric triplex design. This results in more effective operation of the cable for low-tomedium voltage levels. This design results in many advantages when compared to the warm and cold dielectric cables as it has no stray magnetic field, a very low inductance and it uses less superconducting material than other designs.

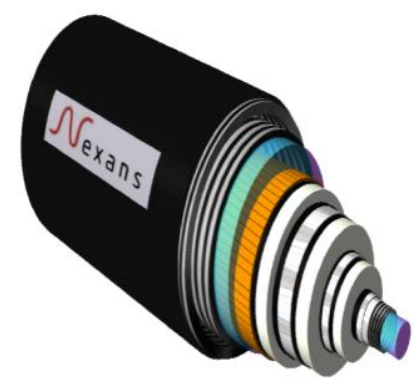

Figure 3: three core HTS cable

Comparison of HTS cable, conventional cable and overhead line is resulted in table1.

Table 1: electrical characteristics example of $120 \mathrm{kv}$ class cable

\begin{tabular}{|c|c|c|c|}
\hline Technology & $\begin{array}{c}\text { Resistan } \\
\text { ce } \\
(\Omega / \mathrm{km})\end{array}$ & $\begin{array}{c}\text { Induc } \\
\text { tance } \\
(\mathrm{mH} / \\
\mathrm{km})\end{array}$ & $\begin{array}{c}\text { Capaci } \\
\text { tance } \\
(\mathrm{nF} / \mathrm{k} \\
\mathrm{m})\end{array}$ \\
\hline $\begin{array}{c}\text { Cold Dielectric } \\
\text { HTS }\end{array}$ & 0.0001 & 0.06 & $\begin{array}{c}200 / 1 . \\
08\end{array}$ \\
\hline $\begin{array}{c}\text { Conventional } \\
\text { XLPE }\end{array}$ & 0.03 & 0.36 & $\begin{array}{c}257 / 1 . \\
40\end{array}$ \\
\hline $\begin{array}{c}\text { Overhead Line } \\
\end{array}$ & 0.08 & 1.26 & $\begin{array}{c}8.8 / 0.0 \\
5\end{array}$ \\
\hline
\end{tabular}

\section{INSULATION OF THE CABLE}

Large availability of insulated HTS conductors results in saving the time, cost, and risk of damage in the manufacturing process of the cable. Usage of insulated HTS cables increase the partial discharge inception voltage(PDIV)of HTS cables. And PDIV is considered the function of dielectric of the cryogen used in the cable. For the cables using liquid nitrogen(LN2) as cryogen are allowed with voltage rating excess of $100 \mathrm{KV}$ [6]. 


\section{International Journal of Engineering Applied Sciences and Technology, 2019 \\ Vol. 4, Issue 6, ISSN No. 2455-2143, Pages 307-312 \\ Published Online October 2019 in IJEAST (http://www.ijeast.com)}

If the same cable is using gaseous Helium(GHe), it was observed that the suitable lower voltage range $<10 \mathrm{KV}$. We are introduced with many methods available to apply insulation onto the HTS tapes like extrusion, dip coating, and heat shrink. After a study on the type of insulation to be used, Heat Shrink is considered as the easy method of insulation to ensure uniform insulation with different thickness of the insulation walls. The main advantage of considering Heat shrink of the insulation of the cable is as it is not directly lied on the cable there will no cause of mechanical stress on the HTS cable.

In the process of identification of alternative dielectric material, a study was done on the insulation of the individual HTS cable which resulted in reducing the mechanical stress and lowers the risk of damaging the insulation or the superconducting material. And this also results in the reduction of complexity of the fabrication process.

Manufacturing techniques of the HTS cable are to be considered, for the type for insulated material to be used for the insulation of the cable. Ion-Beam Assisted as Deposition (IBAD), Rolling Assisted Biaxially Textured Substrates (RABiTS), and Inclined Substrate Deposition (ISD) are mostly used techniques for the manufacturing of a HTS cable. Each of these techniques have different fabrication principles so they have different operating temperatures.[4] For example, HTS tape manufactured by the IBAD technique has a maximum operating temperature of $240^{\circ} \mathrm{C}$ whereas HTS manufactured by RABiTS technique has a maximum operating temperature of $175^{\circ} \mathrm{C}$.

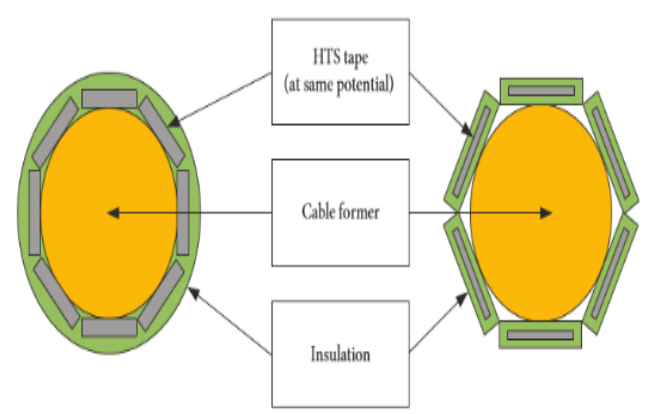

Figure 4: insulation of individual HTS Cable and combined insulation for all the HTS tapes

As discussed before, heat shrink is considered for providing insulation to the HTS cable for which many types of polymers are available. For the material to be used for insulation polytetrafluoroethylene (PTFE), fluorinated ethylene propylene (FEP), polyether ether ketone (PEEK), and polyethylene terephthalate (PET) are tested for several mechanical and

electrical characteristics like shrink temperature, dielectric strength, relative permittivity, volume resistivity, CTE, and thermal conductivity. [4] By this test it was concluded that PTFE, FEP, and PEEK have a shrink temperature greater than $175^{\circ} \mathrm{C}$, the maximum temperature allowable for most bonded HTS tapes. Exceeding this temperature could cause the HTS tape to delaminate and damage the superconducting layer. Therefore, PET heat shrink was selected for further investigations.

PET heat shrink is available in various diameters and wall thicknesses for the insulation of the cable. Uniform finish are obtained by using a heat shrink circumference that is a maximum of $15 \%$ larger than the HTS tape circumference. A Heat shrink has variety of wall thicknesses available in 6.35 , $12.7,19.1,25.4,50.8$, and $76.2 \mu \mathrm{m}$, increasing linearly from 0.5 to 6 times of $12.7 \mu \mathrm{m}$. The reason for usage of several wall thicknesses is to establish a relationship between the thickness of the insulation and the breakdown voltage of the insulating material for the safe operation of the HTS cable.

Cryogen used may have its influence on the breakdown voltage of the heat shrink. LN2 was used for the individual HTS tapes, and GHe is used for the model cable. By the result of the tests conducted it is observed that the relative permittivity of LN2 (1.45) is a closer match to PET (3.3) than that of GHe (1.0). The dielectric strength of LN2 is also much more compared to the dielectric strength of GHe. [4] So, the LN2 may have added additional dielectric strength to the heat shrink and also reducing the electric field enhancement in the voids, which resulted in a higher AC break down voltage when compared to GHe.

\begin{tabular}{|l|l|l|l|l|l|}
\hline Material & $\begin{array}{l}\text { Shrink temp } \\
\left({ }^{\circ} \mathrm{C}\right)\end{array}$ & $\begin{array}{l}\text { Dielectric } \\
\text { strength } \\
(\mathrm{kV} / \mathrm{mm})\end{array}$ & Relative permittivity & $\begin{array}{l}\text { CTE }(\mu \mathrm{m} / \mathrm{m}- \\
\mathrm{K})\end{array}$ & $\begin{array}{l}\text { Thermal conductivity } \\
(\mathrm{W} / \mathrm{m}-\mathrm{K})\end{array}$ \\
\hline PTFE & $346-354$ & $7-24$ & 2.1 & $126-180$ & $0.17-0.30$ \\
\hline FEP & $204-216$ & $20-79$ & $2.0-2.1$ & $100-135$ & $0.19-0.25$ \\
\hline PEEK & $330-360$ & 20 & $2.2-2.8$ & 47 & 0.25 \\
\hline PET & $85-190$ & 17 as & 1 & $10-20$ & 0.15 \\
\hline $\begin{array}{l}\text { Ideal As high as possible } \\
\text { shrink }\end{array}$ & $<175$ & $\begin{array}{l}\text { As high as } \\
\text { possible }\end{array}$ & \\
\hline
\end{tabular}




\section{International Journal of Engineering Applied Sciences and Technology, 2019 \\ Vol. 4, Issue 6, ISSN No. 2455-2143, Pages 307-312 \\ Published Online October 2019 in IJEAST (http://www.ijeast.com)}

\section{BENEFITS OF SUPERCONDUCTING CABLES}

Electric power at an effective current density of over 100 $\mathrm{A} / \mathrm{mm} 2$, which is more than 100 times that of copper cable can be transmitted by Superconducting Cables. This results in the achievement of high capacity power transmission over the cables with more compact size than conventional cables, which greatly reduce construction costs. One of the advantages of using Superconducting Cables when compared to Conventional Cables is its Compactness and High capacity. As the electrical resistance of Superconducting Cable is zero below the critical temperature the transmission losses are reduced due to the use of Superconducting Cables. To maintain the superconducting cable to the required or operating temperature, a coolant from a cooling unit is required to replace for this heat gain. This results in Low Loss Power Transmission and environmental friendly Transmission[7]. As the change in temperature is very slight during the operation of the cable there will be no change in the electrical characteristics which results in the stable operation and long line of the power transmission cable. The usage of these HTS cables eliminates the necessity to gain new of Rights of Way for new Overhead Transmission lines when environmental concerns refuse its installation. Due to its low loss transmission, it reduces the electrical maintenance cost and increases the flexibility of the system.

\section{ENERGY LOSS IN THE CABLE}

Even the conducting materials used for the power transmission are Superconducting there exists practical losses in the AC transmission power cable. Losses across a superconducting cable occurs due to the Hysteresis in the material when the cable is fed with AC supply.[2]

Here we will compare the losses occurring in the conventional cable as well as the HTS cable during operational of the cable.

\section{A. Loss components in Conventional Cable:}

The losses in the conventional cable made of copper and aluminum are well in the field. Loss in the conventional cable consists of four elements: conductor losses, induced losses in sheath, induced losses in steel pipes and dielectric losses.

Conduction losses in the conventional cable occurs due to the resistivity of the conducting material used. The losses Wc can be calculated as:

$\mathrm{Wc}=\mathrm{RI}^{2}$

Where $\mathrm{R}$ is $\mathrm{AC}$ resistance

I is rms current

Induced losses in sheath occurs due to the magnetic field in and around the sheath of the conventional cable. These losses can be reduced by transposition of sheaths. [2] Induction losses are directly proportional to $\mathrm{I}^{2}$.
Induced losses in steel pipes can be seen in pipe type cables. These losses are similar to the induced losses in sheath. Pipe type cables are commonly used in United States.

The dielectric losses are the losses which occur in the insulation material of the cable. This occurs due to non-ideal insulation material. The dielectric losses can be given by:

$\mathrm{Wd}=\omega \mathrm{CU} \mathrm{U}_{0}{ }^{2} \tan \delta$

$\mathrm{C}=2 \pi \varepsilon_{\mathrm{o}} \varepsilon_{\mathrm{r}} / \ln \left(\mathrm{D}_{\mathrm{o}} / \mathrm{D}_{1}\right)$

The losses in a conventional cable are determined by the maximum temperature of the cable and the thermal resistance of the cable. By this we can say that the losses in a conventional cable in quite independent of voltage level and rated current.

\section{B. HTS Cables}

The losses introduced in the HTS Cable are different when compared to the losses occurring in the conventional cable. Even if the losses occurring in the HTS cable are less, they have to be reduced by the liquid nitrogen cooling system.

HTS Cables can be classified into two different forms based on difference in loss based on the temperature of the cable. Cryogen dielectric(CD) design and room temperature dielectric (RTD)design.[2]

Loss occurring in a HTS Cable is an be divided into following based on the occurrence of the losses in the cable. conductor ac loss, thermal leak through thermal insulation, induced losses in shield (only RTD), induced losses in thermal insulation (only RTD), hydraulic losses in LN, pumping losses, and losses in joints and terminations.

For a 3-phase RTD cable system, with no or little separation of phases in the cable the conduction ac losses will occur due to additional magnetic field from the neighboring phases in the cable. This effect in CD Design cables is neglected because sufficient phase separation is expected.

Thermal leak in a HTS Cable occurs by thermal insulation due to a non-ideal insulation and the temperature difference between the surroundings $(-300 \mathrm{~K})$ and the liquid nitrogen ($77 \mathrm{~K})$ of the cable.

The Induced losses in sheath of a RTD Cable occurs in the way as in the Conventional Cable.

Dielectric losses in a HTS cable are similar to the loss in the conventional cable. For CD design cables dielectric losses has to be removed by the liquid nitrogen.

Hydraulic losses occur due to the flow friction of the circulation of liquid nitrogen. These hydraulic losses can be given by:

Whyd $=\mathrm{m} \Delta \mathrm{p}$ lrLN

Where $m^{\circ}$ is the mass flow rate,

$\Delta \mathrm{p}$ is the pressure drop of the flow

$\gamma \mathrm{LN}$ is the mass density

Pumping losses are the energy consumed by the pumping system which is required to apply the pressure difference. The 


\section{International Journal of Engineering Applied Sciences and Technology, 2019 \\ Vol. 4, Issue 6, ISSN No. 2455-2143, Pages 307-312 \\ Published Online October 2019 in IJEAST (http://www.ijeast.com)}

energy consumed by the pumping system is corresponding to the flow losses plus losses in the pump.

Finally in a complete cable system there will be losses in joints and terminators. For a cable system where exists terminations in both the ends of the cable. There even exists joints between cables in the case of long transmission system. loss in the terminations occur from the thermal conduction through the metallic current lead from ambient temperature to liquid nitrogen temperature and resistive losses in the current lead.

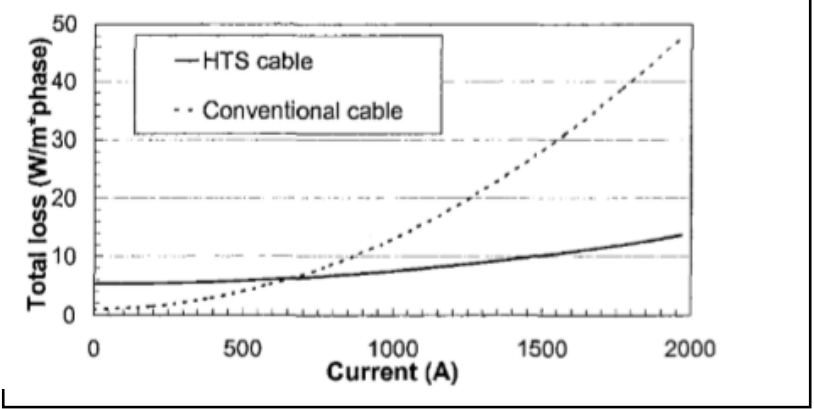

Figure 5: Graphical result of test conducted on HTS cable and Conventional Cable.

\section{VERIFICATION TEST ON SUPERCONDUCTING CABLE}

A verification test was conducted on the superconducting cable in the year 2001-2002 which involved the development of a $100 \mathrm{~m}, 66 \mathrm{kV}, 1 \mathrm{kA}$ class cable. And was successfully implemented with the results tabulated in the below table.

\section{SUMMARY OF VERIFICATION TEST RESULTS}

\begin{tabular}{|l|l|l|}
\hline Item & Results & Targets \\
\hline Current & $2 \mathrm{kA}^{*}$ & $3 \mathrm{kA}$ \\
\hline Voltage & $66 \mathrm{kV}$ & $350 \mathrm{MVA}$ \\
\hline Capacity & $220 \mathrm{MVA} *$ & \\
\hline Dimension & $150 \mathrm{~mm}^{*}$ duct & $3.5 \mathrm{~km}$ \\
\hline Cable unit length & $500 \mathrm{~m}^{* *}$ & \\
\hline $\begin{array}{l}\text { Distance between } \\
\text { cooling stations }\end{array}$ & $1 \mathrm{~km}^{* *}$ & \\
\hline
\end{tabular}

- Voltage characteristics: The voltage test cleared the $66 \mathrm{kV}$ class voltages and achieved the target successfully.

- Transmission Capacity: A 200 MVA transmission capacity was calculated from results of critical current measurement. Whereas, the current superconducting cable is expected to carry around of 350 MVA, the target value of this cable.
- Cable length: A target cable length of $500 \mathrm{~m}$ was kept, taking into consideration both the transportability and the distance between direct labour.

- Distance between cooling systems: The interval of the target cooling system installation is 3 to $5 \mathrm{~km}$, which

is comparable to that of oil supply zones of oil filled cable. As the cooling distance keeps increasing the pressure losses due to the flow of coolant keeps increasing. Therefore, certain steps are to be taken to reduce the losses. These losses can be reduced either by reducing the flow volume of the coolant or by increasing the flow path of the coolant.

\section{CONCLUSION}

In this paper we discussed the design, fabrication and installation of a HTS Cable which results in the reduction of losses when compared to the conventional underground cables used for the transmission of same amount of power. Different fabrication techniques and different materials are named for the HTS Cable. Tests are performed on the different materials for proper insulation of the cable. Finally, as per the results of the tests performed for mechanical and electrical characteristics PTEE is considered as the polymer used for the insulation of the cable by Heat Shrink method. Liquid Nitrogen and Gaseous Helium are used as the coolants in the HTS cables. Experimental results shows that the design of the cable is safe and feasible.

\section{REFERENCE}

[1] D. W. A. Willen et al., Test results of full-scale I-ITS cable models and plans for a $36 \mathrm{kV}, 2 \mathrm{kArms}$ utility demonstration, submitted for publication, Applied Superconductivity Conference, 2000.

[2] Jacob Stergard., "Energy losses of superconducting power transmission cables in the grid", IEEE Transactions on Applied Superconductivity, April 2001, pg.2375-2378.

[3] Peter Cheetham, Jose Viquez, WooJin Kim, Lukas Graber, Chul H. Kim,and Sastry V. Pamidi "HighTemperature Superconducting Cable Design Based on Individual Insulated Conductors" Hindawi Advances in Materials Science and Engineering, 2018, pg no, 1-10.

[4] Wei Pi, Quan Yang, Tengyan Wang, Chang Peng, Yinshun Wang, Qingmei Shi and Jin Dong "Insulation Design and Simulation for Three-phase Concentric High-temperature Superconducting Cable 


\section{International Journal of Engineering Applied Sciences and Technology, 2019 \\ Vol. 4, Issue 6, ISSN No. 2455-2143, Pages 307-312 \\ Published Online October 2019 in IJEAST (http://www.ijeast.com)}

under $10 \mathrm{kV}$ Power System" IEEE Transactions on Applied Superconductivity,2019, pg no,1-4.

[5] Peter Cheetham, Jose Viquez, Lukas Graber, Chul H Kim, Horatio Rodrigo "Novel Design Concept and Demonstration of a Superconducting Gas Insulated Transmission Line" IEEE Transactions on Applied Superconductivity, October 2016,pg no.1-5.

[6] Panpan Chen, Hongjie Zhang, Ming Qiu, Huiming Zhang, Jun Gong, Yuanyuan He, and Min Zhang, "Design and Characteristic Study of a Novel Internal Cooling High Temperature Superconducting Composite Cable With REBCO for Energy Storage Applications", IEEE Transactions on Applied Superconductivity, April 2018, pg no, 48013054801305.

[7] Mbunwe Muncho Josephine, "Development Trends of Superconducting Cable Technology for Power Transmission Applications", Proceedings of the World Congress on Engineering and Computer Science 2015pg no,1-6. 